\title{
МАГНЕТИТОВЫЙ ПЛАСТ В ЭКЗОКОНТАКТЕ МАССИВА НЮД МОНЧЕГОРСКОГО КОМПЛЕКСА: НОВЫЕ ГЕНЕТИЧЕСКИЕ ОГРАНИЧЕНИЯ ПО LA-ICP-MS ДАННЫМ О СОСТАВЕ МАГНЕТИТА
}

Грошев Н.Ю. ${ }^{1}$, Малыгина А.В. ${ }^{1}$, Абрамова В.Д. ${ }^{2}$

${ }^{1}$ Геологический институт КНЦ РАН, Anamumbl,nikolaygroshev@gmail.com

${ }^{2}$ Институт геологии рудных месторождений, петрографии, минералогии и геохимии РАН, Москва

\section{Введение}

В районе участка Габбро 10-й аномалии Мончегорского интрузивного комплекса развиты породы экзоконтакта массива Нюд (рис. 1, а; а также рис. 1 в статье П.В. Припачкина и др. из этого сборника), происхождение которых связывается с различными метасоматическими процессами [1]. Метагаббро и метадиориты экзоконтакта разделены пластом существенно магнетитовых пород (50-90 об. \% Mt). Происхождение магнетитового пласта является предметом продолжающейся дискуссии, в которой метасоматическая модель [1] противопоставляется первично-магматическому механизму формирования [2 и ссылки там]. Как показала Дэр с коллегами [3], элементы-примеси в магнетите играют важную роль в вопросе разделения гидротермально-метаморфогенных и магматических условий образования этого минерала. В настоящей статье мы приводим LA-ICP-MS данные о содержании редких элементов в магнетите из метадиоритов и из руды.

\section{Материалы и методы исследований}

Для того, чтобы определить, является ли магнетитовый пласт магматическим или метаморфогенным (метасоматическим) образованием, был изучен магнетит из двух образцов керна скважины номер 1810. Образец 1810/18.3 отобран из массивных метадиоритов с акцессорным магнетитом, образец 1810/21.4 - из магнетитовой породы пласта, содержащей 50 об. \% магнетита. Зерна магнетита с множественными ламелями ильменита, развитыми в обоих образцах (рис. 1, б и в), изучены на электронном микроскопе Hitachi S-3400N в РЦ «Геомодель» (г. Санкт-Петербург, аналитик В.В. Шиловских). Выделенные относительно однородные участки зерен исследованы на микрозондовом анализаторе MS-46 Сатеса в Геологическом институте КНЦ РАН (г. Апатиты, аналитик Е.Э. Савченко). Анализ магнетита методом LA-ICP-MS выполнен на квадрупольном масс-спектрометре Thermo Xseries с лазерной приставкой New Wave 213 в ИГЕМ РАН (г. Москва, аналитик В.Д. Абрамова). Сканирование зерен магнетита проводилось линейными профилями шириной 40 мкм со скоростью 5 мкм/сек. Частота сканирования 15 Гц, энергия лазера 5-7 Дж/см². Каждому анализу предшествовала 30 секундная регистрация шумового сигнала. Содержания изотопов 23 элементов (табл. 1) рассчитаны в программе Iolite 2.5 путем установки переделов калькуляции на линейном профиле магнетита по спектрам элементов, характерных для свободного от включений минерала; всего сделано 26 расчетов. Для калибровки использовался международный стандартный образец состава GSE-1 G, в качестве внутреннего стандарта применялся ${ }^{57} \mathrm{Fe}$.

\section{Результаты исследований и обсуждение}

Нормированные к континентальной коре спектры распределения редких элементов для акцессорного и рудного магнетита из пород экзоконтакта массива Нюд нанесены на мультиэлементную диаграмму (рис. 2), элементы на которой располагаются в порядке увеличения совместимости с магнетитом в магматической системе. Рудный магнетит в сравнении с акцессорным содержит бо́льшие концентрации совместимых элементов (Co, $\mathrm{V}, \mathrm{Ni}, \mathrm{Cr})$, в то время как акцессорный обогащен умеренно несовместимыми элементами ( $\mathrm{Ta}, \mathrm{Nb}, \mathrm{Cu}, \mathrm{Mo}$ ). Несмотря на различие в концентрациях некоторых элементов ( $\mathrm{Mg}, \mathrm{Al}, \mathrm{V}, \mathrm{Nb}, \mathrm{Mo}, \mathrm{Ta})$, спектры акцессорного и рудного магнетита имеют одинаковый рисунок, что, наряду с распределением этого минерала в разрезе (рис. 1, а), свидетельствует о генетической связи метадиоритов и магнетитового пласта. 


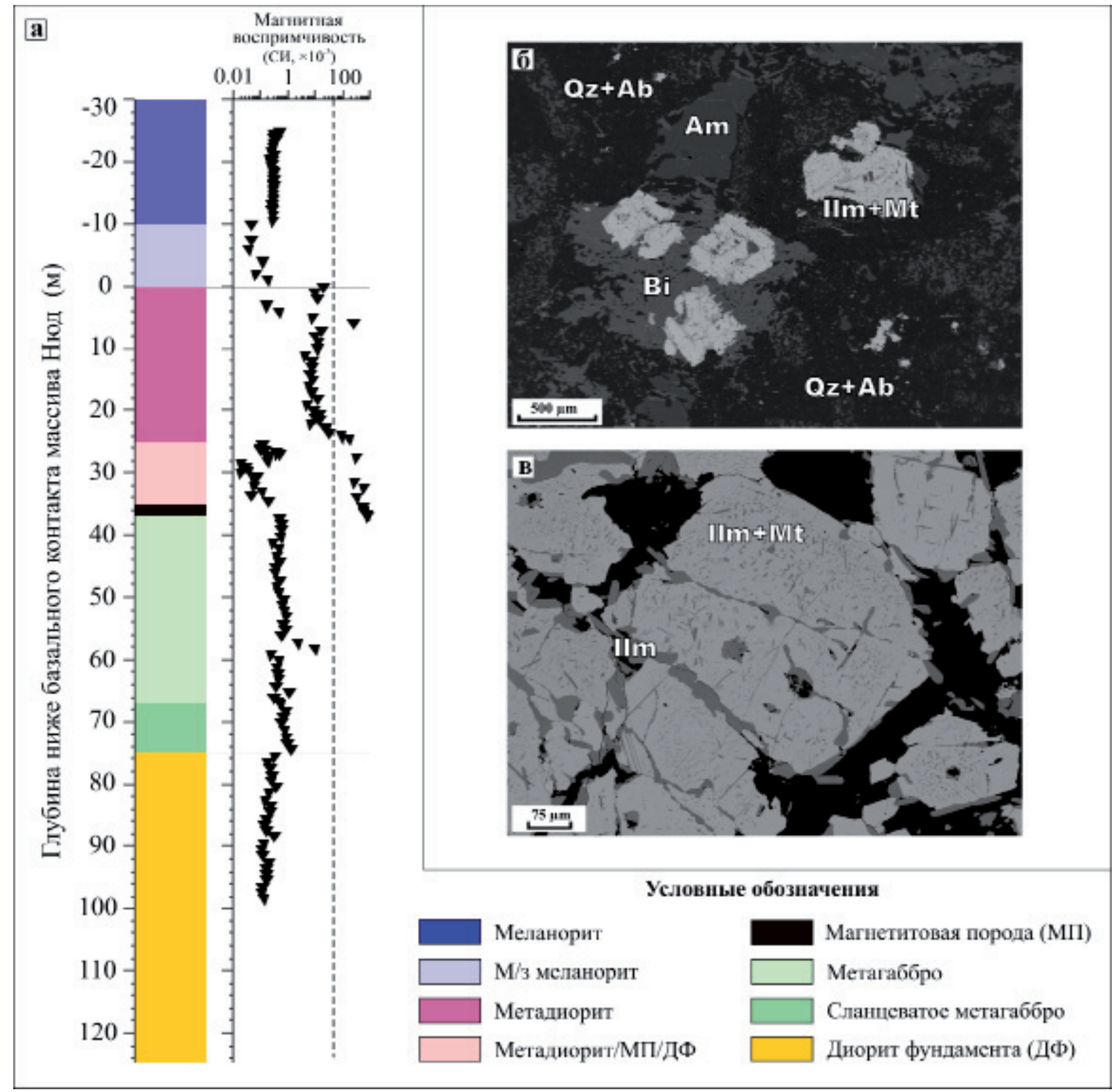

Рис. 1. а - Сводная геологическая колонка экзоконтакта массива Нюд по керну буровых скважин с вариациями магнитной восприимчивости пород. Штриховая линия показывает содержание магнетита в породе, равное 20 об. \%. б - BSE изображение метадиорита с вкраплениями магнетита (обр. 1810/18.3). в - BSE изображение магнетитовой породы (обр. 1810/21.4). Сокращения минералов: Аb - альбит, Am - амфибол, Ві - биотит, Ilm - ильменит, Mt - магнетит, Qz - кварц.

Как акцессорный, так и рудный магнетит по характеру рисунка спектра редких элементов резко отличается от магнетита известных гидротермально-метаморфогенных обстановок и наиболее близок к магматическому магнетиту. Это сходство наиболее заметно в области совместимых и умеренно несовместимых элементов. Изученный магнетит, подобно классическим магнетититам Бушвельда, обогащен $\mathrm{Ti}, \mathrm{Zn}, \mathrm{Co}, \mathrm{V}, \mathrm{Ni}$ и $\mathrm{Cr}$, чего практически не наблюдается в гидротермальнометасоматических обстановках (рис. 2). Низкое отношение $\mathrm{Ni} / \mathrm{Cr}(<1)$ в магнетите из пород экзоконтакта также типично для магматических условий кристаллизации (рис. 3), при которых оба этих элемента являются совместимыми, в отличие от гидротермальных условий, где проявляются различия в растворимости и мобильности между $\mathrm{Ni}$ и $\mathrm{Cr}$. Нетипичное для магматических систем обогащение магнетита экзоконтакта некоторыми несовместимыми элементами (Y, Pb, Zr, Hf), вероятно, объясняется поздней флюидной проработкой первично-магматических пород на завершающих этапах лапландско-кольской коллизионной орогении. 


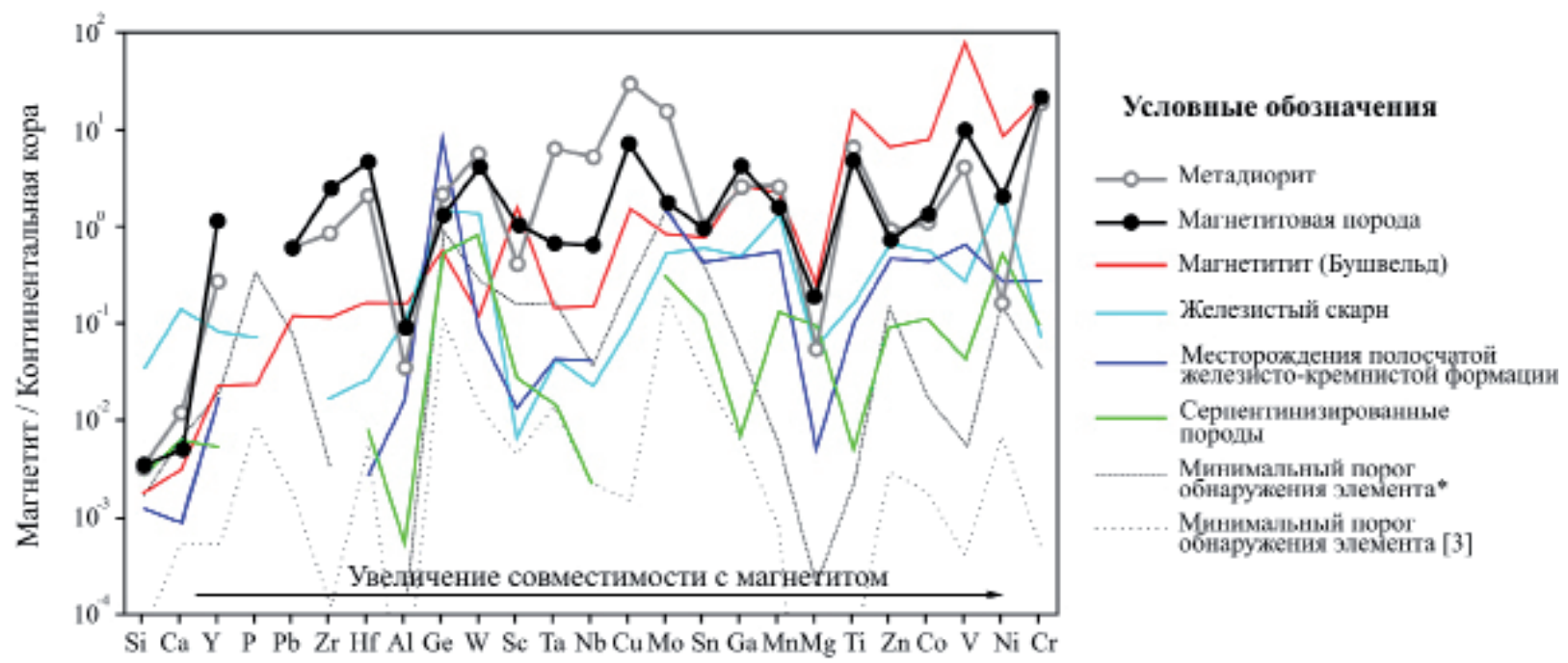

Рис. 2. Нормированная к континентальной коре [4] мультиэлементная вариационная диаграмма для магнетита из метадиорита и магнетитовой породы экзоконтакта массива Нюд в сравнении с магнетитом из типовых обстановок [3]. * - настоящее исследование.

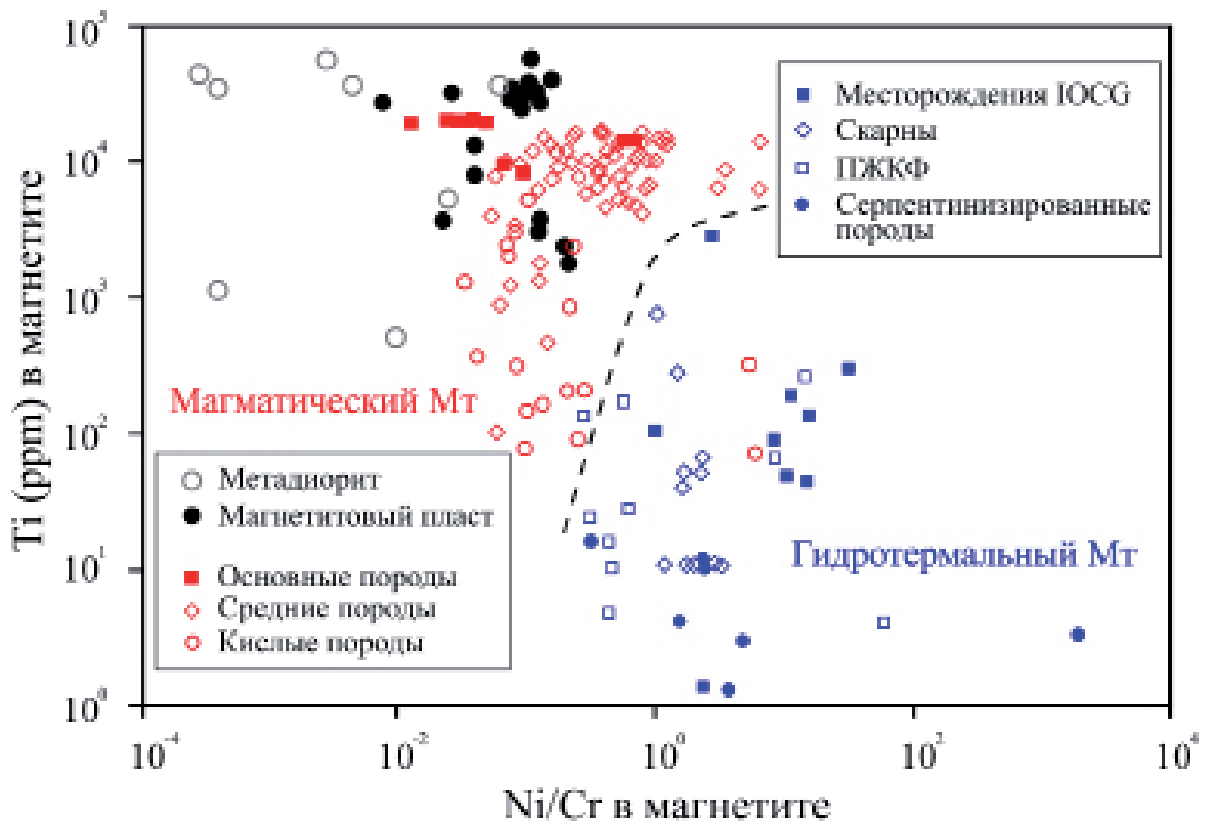

Рис. 3. Диаграмма в координатах концентрация Ti (ppm) против Ni/Cr в магнетите (Мт). Черно-белые символы отражают состав магнетита из метадиорита и магнетитовой породы экзоконтакта массива Нюд; цветными значками показан состав магнетита из магматических (красный) и метаморфогенно-гидротермальных (синий цвет) обстановок по данным [3]. Сокращения: IOCG - Iron Oxide-Copper-Gold; ПЖКФ - месторождения полосчатой железисто-кремнистой формации.

Таким образом, акцессорный и рудный магнетит из экзоконтакта массива Нюд имеет геохимические черты, свидетельствующие, вопреки доминирующим представлениям [1], об его образовании в магматической, а не метасоматической системе. Предлагаемая магматическая модель подразумевает формирование экзоконтактовой ассоциации пород в результате дополнительного внедрения эволюционированного расплава в придонную часть массива Нюд и его дифференциации с формированием массива Габбро 10-й аномалии со своей собственной краевой зоной, зонами метагаббро и метадиоритов с магнетитовыми рудами (рис. 1, а). С учетом полученных новых генетических ограничений интересным в металлогеническом плане представляется изучение концентраций элементов платиновой группы в метадиоритах (см. интрузив Стелла в ЮАР). 
Таблица 1. Вариации содержания элементов-примесей (ppm) в магнетите из метадиорита (1810/18.3) и магнетитовой породы (1810/21.4) по данным LA-ICP-MS.

\begin{tabular}{|c|c|c|c|c|c|c|c|c|c|}
\hline \multirow{2}{*}{\multicolumn{2}{|c|}{$\begin{array}{c}\text { Элемент и } \\
\text { изотоп }\end{array}$}} & \multicolumn{2}{|c|}{ ПО } & \multicolumn{3}{|c|}{ Метадиорит (8*) } & \multicolumn{3}{|c|}{ Магнетитовая порода (18*) } \\
\hline & & \multirow{2}{*}{$\begin{array}{l}\min \\
500\end{array}$} & \multirow{2}{*}{$\frac{\max }{-}$} & \multirow{2}{*}{$\begin{array}{c}\text { средн. } \\
952\end{array}$} & \multirow{2}{*}{$\begin{array}{r}\min \\
\text { НПО }\end{array}$} & \multirow{2}{*}{$\begin{array}{r}\max \\
1510\end{array}$} & \multirow{2}{*}{$\begin{array}{c}\text { средн. } \\
1030\end{array}$} & \multirow{2}{*}{$\begin{array}{l}\min \\
630\end{array}$} & \multirow{2}{*}{$\begin{array}{r}\max \\
1740\end{array}$} \\
\hline $\mathrm{Si}$ & PCMA & & & & & & & & \\
\hline $\mathrm{Ca}$ & PCMA & 300 & - & 664 & НПО & 1900 & НПО & НПО & НПО \\
\hline $\mathrm{Mg}$ & 24 & 6.1 & 21.6 & 1791 & 42 & 4900 & 5739 & 440 & 22000 \\
\hline $\mathrm{Al}$ & 27 & 12.8 & 41.0 & 3288 & 240 & 7300 & 8463 & 640 & 32000 \\
\hline $\mathrm{P}$ & 31 & 195 & 2913 & НПО & НПО & НПО & НПО & НПО & НПО \\
\hline $\mathrm{Sc}$ & 45 & 3.6 & 17.8 & 9.65 & 1.50 & 19.60 & 23.68 & 2.50 & 107.00 \\
\hline $\mathrm{Ti}$ & 47 & 9.4 & 72.8 & 26693 & 514 & 55000 & 22422 & 1790 & 58000 \\
\hline $\mathrm{V}$ & 51 & 0.8 & 5.4 & 593 & 243 & 711 & 1372 & 1000 & 1830 \\
\hline $\mathrm{Cr}$ & 52 & 5.0 & 18.2 & 2738 & 250 & 6900 & 3172 & 477 & 21000 \\
\hline $\mathrm{Mn}$ & 55 & 5.0 & 21.3 & 2302 & 246 & 4700 & 1338 & 150 & 3530 \\
\hline $\mathrm{Co}$ & 59 & 0.5 & 2.1 & 29.8 & 7.3 & 38.3 & 37 & 26.0 & 68.0 \\
\hline $\mathrm{Ni}$ & 60 & 8.9 & 40.4 & 10.2 & 0.3 & 27.0 & 129 & 80.0 & 270.0 \\
\hline $\mathrm{Cu}$ & 63 & 7.2 & 32.4 & $810 * *$ & - & - & $200 * *$ & - & - \\
\hline $\mathrm{Zn}$ & 66 & 10.5 & 36.8 & 72 & 25 & 136 & 62 & 17 & 130 \\
\hline $\mathrm{Ga}$ & 71 & 0.9 & 5.5 & 42 & 35 & 52 & 67 & 42 & 108 \\
\hline $\mathrm{Ge}$ & 74 & 1.1 & 10.8 & 2.85 & 0.80 & 4.60 & 1.83 & 0.41 & 5.60 \\
\hline $\mathrm{Y}$ & 89 & 0.36 & 1.04 & 5.36 & 0.24 & 24.00 & 22.74 & 0.27 & 276.00 \\
\hline $\mathrm{Zr}$ & 90 & 0.49 & 0.92 & 117 & 6 & 394 & 322 & 2 & 2700 \\
\hline $\mathrm{Nb}$ & 93 & 0.30 & 0.77 & 43.06 & 0.32 & 73.00 & 5.32 & 0.17 & 9.60 \\
\hline Mo & 95 & 1.14 & 3.10 & 13.45 & 3.70 & 36.00 & 1.52 & 0.25 & 3.30 \\
\hline $\mathrm{Sn}$ & 118 & 0.72 & 2.71 & 1.65 & 0.43 & 4.00 & 1.72 & 0.30 & 5.40 \\
\hline Hf & 178 & - & - & 7.71 & 0.32 & 14.80 & 17.84 & 0.12 & 78.00 \\
\hline $\mathrm{Ta}$ & 181 & 0.12 & 0.15 & 4.45 & 0.90 & 7.40 & 0.48 & 0.05 & 0.94 \\
\hline W & 182 & 0.30 & 0.72 & 5.49 & 2.60 & 14.00 & 4.45 & 0.30 & 17.40 \\
\hline $\mathrm{Pb}$ & 208 & 0.85 & 2.68 & 6.88 & 1.54 & 11.00 & 7.38 & 1.47 & 24.00 \\
\hline
\end{tabular}

Примечание: РСМА - рентгеноспектральный микроанализ; НПО - ниже порога обнаружения (ПО); * - количество анализов; ** - приведено минимальное содержание меди из серии определений, в которой встречаются нехарактерные для магнетита концентрации (до 2.8 мас. \%), возможно, связанные с присутствием остатков медного напыления после РСМА).

Работа частично поддержана из средств РФФИ (16-05-00367, 15-35-20501) и гранта SEGCF (Канада), присужденного А.В.М. Работа выполнена в рамках госзадания № 0231-2015-0002.

\section{Литература}

1. Козлов Е.К. Естественные ряды пород никеленосных интрузий и их металлогения. Л: Наука. 1973.288 с.

2. Малыгина А.В., Грошев Н.Ю., Кариковски Б.Т. и др. О генезисе «магнетитового пласта» в массиве Габбро десятой аномалии Мончегорского плутона по данным U-Pb SHRIMP-II-датирования циркона и бадделеита из метадиоритов / Новое в познании процессов рудообразования: Сборник материалов. М.: ИГЕМ РАН. 2017. С. 187-190.

3. Dare S. A. S., Barnes S., Beaudoin G. et al. Trace elements in magnetite as petrogenetic indicators // Mineralium Deposita. 2014. V. 49. P. 785-796.

4. Rudnick R. L. and Gao S. 3.01. Composition of the Continental Crust / Treatise on Geochemistry. 2003. V. 1. P. 1-64. 